\title{
Prediction of Outcome after Percutaneous Coronary Intervention for the Acute Coronary Syndrome
}

\author{
Annapoorna S. Kini, MD, Paul C. Lee, MD, Cristina A. Mitre, MD, Michael C. Kim, MD, \\ Mazullah Kamran, MD, Mary E. Duffy, NP, Jonathan D. Marmur, MD, Samin K. Sharma, MD
}

BACKGROUND: The seven-component Thrombolysis In Myocardial Infarction (TIMI) score has been used to risk stratify, and to guide the medical management of, patients with unstable angina or non-ST-elevation myocardial infarction. We assessed the usefulness of the risk score in predicting in-hospital and 30-day outcomes in such patients who were undergoing percutaneous coronary intervention.

METHODS: Using the TIMI score, 2501 patients with unstable angina or non-ST-elevation myocardial infarction were divided into low-risk (zero to two risk factors; $\mathrm{n}=974$ ), intermediaterisk (three to four risk factors; $\mathrm{n}=1339$ ), and high-risk (five to seven risk factors; $\mathrm{n}=188$ ) groups, and outcomes were compared.

RESULTS: Angiographic/clinical success and the rate of minor procedural events were similar among the three groups. A higher TIMI risk score was associated with more cardiac comorbid conditions and more complicated angiographic lesions: longer lesions $(P=0.0009)$, more thrombotic lesions $(P=$
$0.03)$, more multivessel disease $(P<0.0001)$, and more American College of Cardiology/American Heart Association type B2/C lesions $(P=0.05)$. Although the risk score did not predict interventional technical success or intraprocedural complications, a high score was associated with prolonged hospital stay, higher postprocedural peak troponin levels, and 30-day major adverse cardiac events. Stepwise logistic regression showed that in conjunction with lesion length and patient sex, a high score was an independent predictor of 30-day major adverse cardiac events (odds ratio $=2.3 ; 95 \%$ confidence interval: 1.1 to 4.1 ; C statistic $=0.62)$.

CONCLUSION: Although a higher TIMI risk score in patients with unstable angina or non-ST-elevation myocardial infarction who were undergoing percutaneous coronary intervention correlated with adverse clinical outcome, the score alone cannot be used to guide diagnostic or therapeutic strategies. Am J Med. 2003;115:708-714. (C2003 by Excerpta Medica Inc.
$\mathrm{T}$ he risk of death or ischemic events in patients with unstable angina or non-ST-segment elevation myocardial infarction varies widely due to the heterogeneous nature of the disease. Risk stratification of these patients is essential for predicting prognosis, planning treatment strategy, and providing information to patients and relatives. The severity of the clinical presentation influences the type of treatment, such as use of platelet glycoprotein IIb/IIIa inhibitors or percutaneous coronary intervention, as patients with variable degrees of risk may differ considerably in the extent of benefit gained from specific interventions $(1,2)$. The Thrombolysis In Myocardial Infarction (TIMI) investigators developed a risk score for adverse outcome based on seven predictors in patients in the TIMI-11B and Efficacy and Safety of Subcutaneous Enoxaparin in Non-Q-Wave Coronary Events (ESSENCE) trials (3). The TIMI risk score is commonly used for risk stratification and thera-

From the Cardiac Catheterization Laboratory of the Cardiovascular Institute, Mount Sinai Hospital, New York, New York.

Dr. Lee is supported by the Canadian Institute of Health Research Postdoctoral Fellowship Award.

Requests for reprints should be addressed to Samin K. Sharma, MD, Mount Sinai Hospital, Box 1030, One Gustave L. Levy Place, New York, New York 10029-6574, or samin.sharma@msnyuhealth.org.

Manuscript submitted December 13, 2002, and accepted in revised form September 9, 2003. peutic decision-making in patients with unstable angina or non-ST-segment elevation myocardial infarction (1), who show considerable variability in terms of periprocedural enzyme release, hospital stay, and other ischemic events (4-7). However, it is not known if this risk score can also be used to predict outcomes in these patients. In the present study, we assessed the utility of the TIMI risk score in predicting procedural, in-hospital, and 30-day outcomes in patients with unstable angina or non-STsegment elevation myocardial infarction who were undergoing percutaneous coronary intervention.

\section{METHODS}

\section{Patients}

Patients with unstable angina or non-ST-segment elevation myocardial infarction who had undergone percutaneous coronary intervention at Mount Sinai Hospital, New York, from July 1999 to May 2001, were identified from the hospital's interventional database. The TIMI risk score was calculated using the following established clinical variables: age $\geq 65$ years, three or more coronary risk factors (diabetes, hypertension, hyperlipidemia, smoking, positive family history), known coronary stenosis $\geq 50 \%$, ST-segment deviation at presentation, two or more anginal events in the last 24 hours, use of aspirin 
TIMI Score to Predict Short-term Outcome after Percutaneous Coronary Intervention/Kini et al

Table 1. Distribution of Patients by TIMI Risk Score and Individual Score Components

\begin{tabular}{|c|c|c|c|c|c|c|c|c|}
\hline $\begin{array}{l}\text { TIMI } \\
\text { Risk } \\
\text { Score }\end{array}$ & $\begin{array}{c}\text { No. of } \\
\text { Patients }\end{array}$ & $\begin{array}{c}\text { Age } \\
\geq 65 \text { years }\end{array}$ & $\begin{array}{c}\text { Aspirin } \\
\text { Use in } \\
\text { Last } 7 \text { Days }\end{array}$ & $\begin{array}{l}\geq 3 \text { Coronary } \\
\text { Risk Factors }\end{array}$ & $\begin{array}{c}\text { Known } \\
\text { Coronary } \\
\text { Stenosis } \geq 50 \%\end{array}$ & $\begin{array}{c}\geq 2 \text { Anginal } \\
\text { Events in Last } \\
24 \text { Hours }\end{array}$ & $\begin{array}{c}\text { Elevated } \\
\text { Cardiac Marker } \\
\text { Levels }\end{array}$ & $\begin{array}{l}\text { ST-segment } \\
\text { Deviation at } \\
\text { Presentation }\end{array}$ \\
\hline & & \multicolumn{7}{|c|}{ Number (\%) } \\
\hline 0 & 28 & 0 & 0 & 0 & 0 & 0 & 0 & 0 \\
\hline 1 & 238 & $47(20)$ & $107(45)$ & $34(14)$ & $14(6)$ & $3(1)$ & $29(12)$ & $4(2)$ \\
\hline 2 & 708 & $303(43)$ & $529(75)$ & $284(40)$ & $165(23)$ & $41(6)$ & $70(10)$ & $24(3)$ \\
\hline 3 & 844 & $515(61)$ & $717(85)$ & $512(61)$ & $492(58)$ & $114(14)$ & $116(14)$ & $66(8)$ \\
\hline 4 & 495 & $374(76)$ & $456(92)$ & $391(79)$ & $397(80)$ & $206(42)$ & $89(18)$ & $67(14)$ \\
\hline 5 & 157 & $136(87)$ & $152(97)$ & $137(87)$ & 139 (89) & $134(85)$ & $51(32)$ & $36(23)$ \\
\hline $6 / 7$ & 31 & $29(94)$ & $31(100)$ & $30(97)$ & $29(94)$ & $29(94)$ & $23(74)$ & $15(48)$ \\
\hline Total & 2501 & $1404(56)$ & $1992(80)$ & $1388(56)$ & $1236(49)$ & $527(21)$ & 378 (15) & $212(8)$ \\
\hline
\end{tabular}

${ }^{*}$ Risk factors include diabetes, hypertension, hyperlipidemia, smoking, and positive family history.

TIMI $=$ Thrombolysis In Myocardial Infarction.

within the previous 7 days, and elevated levels of cardiac markers (Table 1). Patients received 1 point for each risk factor, with a maximum score of 7 and a minimum score of 0 . Low risk was defined as zero to two risk factors, intermediate risk was defined as three to four risk factors, and high risk was defined as five to seven risk factors (3). Serial electrocardiograms were taken and cardiac enzyme levels (creatine kinase-MB, troponin I) were measured before and after coronary intervention. Patients were followed for in-hospital cardiac and ischemic events. All patients were followed clinically for events at 30 days by telephone call to the patient or private physician. Interventions involved use of conventional technique, aspirin, clopidogrel, low-dose heparin $(60 \mathrm{IU} / \mathrm{kg})$, or glycoprotein IIb/IIIa inhibitors (4). The study was approved by the hospital's Institutional Review Board.

\section{Definitions}

Creatine kinase-MB isoenzyme levels were measured using the mass technique; elevated values were defined as levels $\geq 16 \mathrm{U} / \mathrm{L}$, which were further divided into one to three times, four to five times, and greater than five times the baseline value. Troponin I levels $\geq 2.0 \mathrm{ng} / \mathrm{mL}$ were considered elevated. Procedural events were defined as angiographic dissection, side branch closure, distal thromboembolism, slow flow/no flow, and persistent chest pain. Angiographic success was defined as $<30 \%$ diameter obstruction postprocedurally with TIMI III flow, and clinical success as indication of angiographic success of at least one lesion without urgent bypass surgery, Q-wave or large non-Q-wave myocardial infarction, or in-hospital death. Major adverse cardiac events at 30 days were defined as death, repeat intervention, or new myocardial infarction with creatine kinase-MB levels more than three times the baseline value.

\section{Statistical Analysis}

The data were analyzed with JMP 5.1a (SAS Institute, Cary, North Carolina) and SPSS 11.0 (Chicago, Illinois).
Categorical variables were compared using the chisquared test. Comparisons of continuous variables, which did not violate normality assumption (as assessed by the Kolmogorov-Smirnov-Lilliefors test), were performed using analysis of variance. The Kruskal-Wallis test was used to compare nonnormally distributed continuous variables. All continuous data are expressed as means \pm SD unless they violate normality assumption, in which case the data are presented as medians with the interquartile range.

Logistic regression models were used to examine the relation of TIMI risk groups to outcomes. The TIMI score was converted into a categorical variable (high risk vs. non-high risk) because of its nonlinear relation with 30day major adverse cardiac events. We performed forward logistic stepwise regression using TIMI scores and preprocedural patient and angiographic data, including sex, artery, left ventricular ejection fraction, stenosis, lesion length, American College of Cardiology/American Heart Association (ACC/AHA) lesion type, glycoprotein IIb/ IIIa inhibitor use, TIMI flow, and aspirin or beta-blocker use. Age, diabetes, hypertension, smoking, and hyperlipidemia were excluded from the model because they are already included in the TIMI risk score calculation and pose a problem with covariate collinearity for the prediction of 30-day major adverse cardiovascular events. Univariate logistic regression was first performed for each covariate (8). Covariates with a significance level of $P$ $<0.20$ were entered into the multivariable model. A backwards elimination procedure (cutoff of $P>0.10$ ) was then used to arrive at a final regression model. The initial model showed that lesion length is a significant covariate as a continuous variable. We converted lesion length into a categorical variable after determining that a cutoff of 12 $\mathrm{mm}$ would minimize the residual log likelihood chisquare, using recursive partitioning as implemented in SAS/JMP (9). The reported $P$ value of the optimally di- 
Table 2. Baseline Characteristics of Patients by Risk Group

\begin{tabular}{lcccc}
\hline \multicolumn{1}{c}{ Characteristic } & $\begin{array}{c}\text { Low Risk } \\
(\mathrm{n}=974)\end{array}$ & $\begin{array}{c}\text { Intermediate Risk } \\
(\mathrm{n}=1339)\end{array}$ & $\begin{array}{c}\text { High Risk } \\
(\mathrm{n}=188)\end{array}$ & P Value \\
\cline { 2 - 4 } & \multicolumn{3}{c}{ Number $(\%)$ or Mean $\pm \mathrm{SD}$} \\
Age (years) & $62 \pm 12$ & $68 \pm 11$ & $74 \pm 9$ & $<0.0001$ \\
Male sex & $682(70)$ & $884(66)$ & $113(60)$ & 0.03 \\
Diabetes mellitus & $273(28)$ & $643(48)$ & $122(65)$ & $<0.0001$ \\
History of hypertension & $760(78)$ & $1232(92)$ & $184(98)$ & $<0.0001$ \\
History of hyperlipidemia & $623(64)$ & $1044(78)$ & $156(83)$ & $<0.0001$ \\
Prior myocardial infarction & $117(12)$ & $549(41)$ & $115(61)$ & $<0.0001$ \\
$\geq 2$ Anginal events & $44(5)$ & $320(24)$ & $163(87)$ & $<0.0001$ \\
Left ventricular ejection & $54.6 \pm 9.4$ & $51.9 \pm 11.4$ & $49.8 \pm 11.8$ & $<0.0001$ \\
$\quad$ & & & \\
fraction (\%) & $28(3)$ & $133(10)$ & $51(27)$ & $<0.0001$ \\
Elevated cardiac markers & $99(10)$ & $205(15)$ & $74(39)$ & $<0.0001$ \\
Low-density lipoprotein & $506(52)$ & $723(54)$ & $120(64)$ & 0.01 \\
$\quad$ & & & \\
Current smokers & $175(18)$ & $187(14)$ & $19(10)$ & 0.01 \\
Prior aspirin use & $636(65)$ & $1173(88)$ & $183(97)$ & $<0.0001$ \\
Beta-blocker use & $448(46)$ & $857(64)$ & $139(74)$ & $<0.0001$ \\
ACE inhibitor use & $273(28)$ & $616(46)$ & $113(60)$ & $<0.0001$ \\
Statin use & $487(50)$ & $897(67)$ & $143(76)$ & $<0.001$ \\
\hline
\end{tabular}

$\mathrm{ACE}=$ angiotensin-converting enzyme.

chotomized lesion length variable would be artificially low when compared with the original continuous lesion length variable. Model discrimination was assessed by $\mathrm{C}$ statistic, which is equivalent to the area under the receiver operating characteristic curve. We tested our model calibration with the Hosmer-Lemeshow goodness-of-fit test. Significance of each covariate was tested using the Wald statistic. C statistic comparison was performed using the DeLong nonparametric Mann-Whitney test (10) based on an SAS macro (version 8.02; Cary, North Carolina) written by DeLong. A $P$ value $<0.05$ was considered significant.

\section{RESULTS}

A total of 2501 consecutive patients were analyzed, of whom 974 (39\%) were in the low-risk, 1339 were in intermediate-risk (54\%), and 188 (8\%) were in high-risk groups (Table 2). There were more women in the highrisk group than in the low- and intermediate-risk groups $(P=0.03)$. Patients in the higher-risk group had lower left ventricular ejection fraction $(P<0.0001)$ than did patients in the lower-risk groups, as well as used betablockers, angiotensin-converting enzyme inhibitors, and statins more frequently (all $P<0.001$ ).

\section{Associations between Risk Group and Angiographic Variables}

Patients in the high-risk group generally had more complicated lesions (Table 3 ) than did patients in the lower- risk groups. They also were more likely to have ACC/ AHA type B2/C lesions and longer lesions, as well as a higher prevalence of multivessel disease, thrombus, and a history of coronary artery bypass graft surgery. Saphenous vein grafts and in-stent restenosis were also more common in the high-risk group (Table 3 ). While pre- and postprocedural TIMI flow was not statistically different among the three risk groups, postprocedural minimum lumen diameter was slightly lower in the high-risk group $(P=0.05)$.

Procedural success rates were similar among the three risk groups (Table 4), even though different types of interventional devices were used. Stenting with or without rotational atherectomy was used in $77 \%$ in the lowrisk group, $67 \%$ in the intermediate-risk group, and 63\% in the high-risk group $(P=0.0006)$. Although the preprocedural use of glycoprotein IIb/IIIa inhibitors was higher in the high-risk group, use of these agents was lower in this group during percutaneous coronary intervention (Table 3), attributable to a higher incidence of saphenous vein graft and interventions for restenotic lesions. After adjusting for restenosis and bypass surgery, a high TIMI score appeared to be somewhat associated with increased intraprocedural glycoprotein IIb/IIIa inhibitor use (odds ratio $[\mathrm{OR}]=1.37 ; 95 \%$ confidence interval $[\mathrm{CI}]: 0.8$ to $2.3 ; P=0.46$ ). The maximum activated clotting time was similar in all groups (Table 3), with a comparable major vascular bleeding incidence of $1.1 \%$ (Table 4). 
Table 3. Procedural Variables by Risk Group

\begin{tabular}{|c|c|c|c|c|}
\hline Variable & $\begin{array}{l}\text { Low Risk } \\
(\mathrm{n}=974)\end{array}$ & $\begin{array}{l}\text { Intermediate Risk } \\
\quad(\mathrm{n}=1339)\end{array}$ & $\begin{array}{l}\text { High Risk } \\
(\mathrm{n}=188)\end{array}$ & $P$ Value \\
\hline & \multicolumn{3}{|c|}{ Number $(\%)$ or Mean \pm SD } & \\
\hline 3-Vessel coronary artery disease & $156(16)$ & $375(28)$ & $73(39)$ & $<0.0001$ \\
\hline Previous coronary artery bypass graft surgery & $70(7)$ & $356(27)$ & $84(45)$ & $<0.0001$ \\
\hline Artery intervened & & & & $<0.0001$ \\
\hline Left anterior descending & $423(43)$ & $476(35)$ & $61(32)$ & \\
\hline Right coronary & $236(24)$ & $355(27)$ & $45(24)$ & \\
\hline Circumflex & $282(29)$ & $358(27)$ & $42(22)$ & \\
\hline Left main & $2(0.2)$ & $13(1.0)$ & $5(2.7)$ & \\
\hline Saphenous vein graft & $27(3)$ & $118(9)$ & $32(17)$ & \\
\hline Left internal mammary artery & $3(0.3)$ & $13(1.0)$ & $2(1.1)$ & \\
\hline ACC/AHA type B2/C lesion & $770(79)$ & $1085(81)$ & $162(86)$ & 0.05 \\
\hline Preprocedural TIMI flow $<3$ & $126(13)$ & $183(14)$ & $22(13)$ & 0.65 \\
\hline Postprocedural TIMI flow $<3$ & $46(5)$ & $65(5)$ & $7(4)$ & 0.88 \\
\hline Thrombus & $11(1)$ & $28(2)$ & $6(3)$ & 0.03 \\
\hline Lesion length (mm) & $12.4 \pm 6.0$ & $13.3 \pm 6.6$ & $15.2 \pm 6.5$ & 0.0009 \\
\hline Reference vessel size (mm) & $3.2 \pm 0.5$ & $3.2 \pm 0.5$ & $3.2 \pm 0.6$ & 0.72 \\
\hline Preprocedural minimum lumen diameter (mm) & $0.49 \pm 0.36$ & $0.45 \pm 0.36$ & $0.48 \pm 0.36$ & 0.30 \\
\hline Postprocedural minimum lumen diameter ( $\mathrm{mm}$ ) & $2.96 \pm 0.53$ & $2.90 \pm 0.62$ & $2.88 \pm 0.64$ & 0.05 \\
\hline Preprocedural glycoprotein inhibitor use & $146(15)$ & $174(13)$ & $45(24)$ & $<0.0001$ \\
\hline Intraprocedural glycoprotein inhibitor use & $721(74)$ & $964(72)$ & $103(55)$ & $<0.0001$ \\
\hline Overall glycoprotein inhibitor use & $867(89)$ & $1138(85)$ & $149(79)$ & $<0.0001$ \\
\hline Intervention for restenotic lesions & $51(5)$ & $284(21)$ & $64(27)$ & $<0.0001$ \\
\hline Maximum activated clotting time (seconds) & $283 \pm 75$ & $281 \pm 75$ & $287 \pm 65$ & 0.69 \\
\hline
\end{tabular}

ACC/AHA $=$ American College of Cardiology/American Heart Association; TIMI = Thrombolysis In Myocardial Infarction.

\section{Associations between Risk Group and Outcome}

Although the likelihood of minor procedural events was not statistically different among the three groups, patients in the high-risk group generally had greater increases in creatine kinase-MB levels, as well as higher peak and troponin I values, compared with the low- and intermediate-risk groups (Table 4). In addition, longer hospital stays were more common $(P<0.0001)$ in the high-risk group, in whom the incidence of 30-day major adverse cardiac events was also higher, predominantly because of a trend towards greater creatine kinase-MB elevation.

Table 4. Outcome by Risk Group

\begin{tabular}{|c|c|c|c|c|}
\hline Outcome & $\begin{array}{l}\text { Low Risk } \\
(\mathrm{n}=974)\end{array}$ & $\begin{array}{l}\text { Intermediate Risk } \\
\quad(\mathrm{n}=1339)\end{array}$ & $\begin{array}{l}\text { High Risk } \\
(\mathrm{n}=188)\end{array}$ & $P$ Value \\
\hline & \multicolumn{3}{|c|}{ Number $(\%)$, Mean $\pm \mathrm{SD}$, or Median (Interquartile Range) } & \\
\hline Minor/major procedural complication & $90(9)$ & $135(10)$ & $21(11)$ & 0.64 \\
\hline Major bleeding & $11(1.1)$ & $17(1.3)$ & $2(1.1)$ & 0.93 \\
\hline Clinical success & $958(98.4)$ & $1323(98.8)$ & $185(98.4)$ & 0.68 \\
\hline Any creatine kinase-MB elevation & $196(20)$ & $228(17)$ & $52(28)$ & 0.006 \\
\hline Peak creatine kinase-MB (U/L) & $7.2(1.0-13.8)$ & $7.7(1.6-13.0)$ & $8.8(0.1-17.9)$ & 0.08 \\
\hline Troponin I level $\geq 2.0 \mathrm{ng} / \mathrm{mL}$ & $214(22)$ & $301(23)$ & $73(39)$ & $<0.001$ \\
\hline Peak troponin I (ng/mL) & $0.001(0.00-1.40)$ & $0.001(0.00-1.80)$ & $0.65(0.00-5.70)$ & $<0.001$ \\
\hline Length of stay (days) & $1(1-1)$ & $1(1-1)$ & $1(1-2)$ & $<0.0001$ \\
\hline Postprocedural stay $>1$ day & $218(6)$ & $77(5)$ & $90(8)$ & $<0.0001$ \\
\hline 30-Day major adverse cardiac events & $60(6)$ & $70(5)$ & $19(10)$ & 0.03 \\
\hline Death & $1(0.1)$ & 0 & $2(1)$ & \\
\hline Reintervention & $7(0.7)$ & $11(1)$ & $3(2)$ & \\
\hline Myocardial infarction & $52(5)$ & $59(4)$ & $14(7)$ & \\
\hline
\end{tabular}

* Defined as creatine kinase-MB level more than three times the baseline value. 
Table 5. Prolonged Length of Stay after Percutaneous Coronary Intervention and 30-Day Major Adverse Cardiac Events, by TIMI Risk Score

\begin{tabular}{lccc}
\hline $\begin{array}{c}\text { TIMI Risk } \\
\text { Score }\end{array}$ & $\begin{array}{c}\text { No. of } \\
\text { Patients }\end{array}$ & $\begin{array}{c}\text { Postprocedural } \\
\text { Stay }>\text { 1 Day }\end{array}$ & $\begin{array}{c}\text { 30-Day Major } \\
\text { Adverse Cardiac } \\
\text { Event Rate }^{\dagger}\end{array}$ \\
\hline 0 & 28 & $25.0 \%$ & $1.3 \%$ \\
1 & 238 & $26.9 \%$ & $3.3 \%$ \\
2 & 708 & $20.8 \%$ & $4.8 \%$ \\
3 & 844 & $24.1 \%$ & $3.2 \%$ \\
4 & 495 & $30.0 \%$ & $4.1 \%$ \\
5 & 157 & $45.2 \%$ & $6.4 \%$ \\
$6 / 7$ & 31 & $38.7 \%$ & $18.2 \%$ \\
\hline
\end{tabular}

${ }^{\star} P<0.0001 ;$ C statistic $=0.56$.

${ }^{\dagger}$ For TIMI score: $P=0.06$; $\mathrm{C}$ statistic $=0.53$.

TIMI $=$ Thrombolysis In Myocardial Infarction.

TIMI risk score correlated with the probability of a prolonged hospital stay $($ Table $5 ; P<0.0001 ; \mathrm{C}$ statistic $=$ $0.56)$. Higher TIMI score was associated with increased 30 -day major adverse cardiac events $(P=0.06)$, although a better logistic model fit could be obtained after cubic transformation of the TIMI score $(P=0.01)$. The relation between TIMI score and 30-day event rate is not linear because in the higher-risk group there is a disproportionally larger increase in cardiac event rate for every 1-point increase in TIMI score. The incidence of 30-day major adverse cardiac events for a TIMI score of 0 to 4 (low/ intermediate risk) was similar, but statistically higher for a score of 5 to 7 (high risk) (Table 4; $P=0.03$ ).

The logistic regression model (Table 6; $P<0.0001$ ) revealed that a high TIMI score was a modest predictor of 30 -day major adverse cardiac events $(\mathrm{OR}=2.3 ; 95 \% \mathrm{CI}$ : 1.1 to $4.1 ; P=0.01)$. In conjunction with lesion length and sex, the model had a C statistic of 0.62 .

\section{DISCUSSION}

We found that a higher TIMI risk score was associated with more cardiac comorbid conditions and more com-

Table 6. Multivariate Model of Major Adverse Cardiac Events at 30 Days

\begin{tabular}{lcc}
\hline \multicolumn{1}{c}{ Variable } & \multicolumn{2}{c}{$\begin{array}{c}\text { 30-Day Major Adverse } \\
\text { Cardiac Events* }\end{array}$} \\
\hline & $\begin{array}{c}\text { Odds Ratio } \\
(95 \% \text { Confidence Interval })\end{array}$ & $\begin{array}{c}P \\
\text { Value }\end{array}$ \\
\cline { 2 - 3 } High TIMI score & $2.30(1.12-4.13)$ & 0.01 \\
Lesion length $\geq 12 \mathrm{~mm}$ & $1.87(1.20-2.95)$ & 0.006 \\
Female sex & $1.43(1.23-2.96)$ & 0.004 \\
\hline \multirow{*}{*}{$P<0.0001$ for model; C statistic $=0.62 ; P=0.86$ with Hosmer- } \\
Lemeshow goodness-of-fit test. \\
TIMI = Thrombolysis In Myocardial Infarction.
\end{tabular}

plicated angiographic lesions (longer lesions, more thrombotic lesions, more multivessel disease, and more ACC/AHA type B2/C lesions). Although the risk score did not predict procedural technical success or the likelihood of intraprocedural complications, it correlated with length of hospital stay and postprocedural enzyme release. The score alone was only very modestly predictive of 30-day major adverse cardiac events, although its discriminatory ability somewhat improved when used in conjunction with patient sex and lesion length.

Other studies of the prediction of postprocedural outcome, which included patients with ST-elevation myocardial infarction who were in cardiogenic shock as well as elective stable angina patients, have reported a C statistic ranging from 0.78 to 0.9 (11-14). The original study describing the derivation of the TIMI risk score reported a C statistic of 0.63 (3). Application of the risk score to the Veterans Affairs Non-Q-Wave Myocardial Infarction Strategies In-Hospital (VANQWISH) database (which consisted of non-ST-elevation myocardial infarction or unstable angina patients undergoing either conservative or aggressive therapy) showed that the TIMI risk score was substantially more predictive of events in the conservative strategy group $(\mathrm{C}$ statistic $=0.62)$ than in the invasive strategy group $(\mathrm{C}$ statistic $=0.53)(15)$. Similarly, we found that the TIMI risk score by itself was only very modestly predictive $(\mathrm{C}$ statistic $=0.53)$, but a simple modification incorporating three variables (TIMI score, lesion length, and sex) slightly improved predictive power $(\mathrm{C}$ statistic $=0.62)$. Although a higher score correlated with adverse clinical outcome, no combinations of factors are sufficiently predictive to guide diagnostic or therapeutic strategy.

Prior studies have identified various clinical (unstable angina, postinfarct angina, diabetes, left ventricular ejection fraction) and angiographic (multivessel disease, thrombus, calcified lesions, ACC/AHA B2/C lesions, vein graft lesion) characteristics as being associated with the risk of procedural, in-hospital, and short-term events after intervention (5-7). However, the risk factors vary throughout the literature, especially with the availability of newer devices and adjunctive pharmacotherapy, which have been reported to increase the procedural success of coronary intervention to over $96 \%$, with slightly lower rates in patients with acute coronary syndrome and complex coronary lesion morphology as compared with stable patients (6). Therefore, it is important to identify high-risk patients undergoing percutaneous coronary intervention who could benefit from other adjunct pharmacotherapy such as low molecular weight heparin, glycoprotein IIb/IIIa inhibitors, or clopidogrel, in addition to appropriate interventional devices $(2,16-23)$. The TIMI risk score was established to facilitate the triage of patients with acute coronary syndromes. In the Treat angina with Aggrastat and determine Cost of Therapy with 
an Invasive or Conservative Strategy (TACTICS) trial, early angioplasty with a glycoprotein IIb/IIIa inhibitor (tirofiban) was superior to a conservative approach at 30 days and 6 months in patients with the acute coronary syndrome, especially those with elevated troponin levels and an intermediate-to-high TIMI risk score (24). We found that TIMI score alone was only modestly useful in predicting postprocedural outcome, and would need to be used in conjunction with other information, such as lesion length and patient sex, to have better predictive value.

The lower intraprocedural use of glycoprotein IIb/IIIa inhibitors in high-risk patients may be explained by the higher prevalence of older patients, who have an increased risk of vascular and nonvascular bleeding, and higher rates of saphenous vein graft and in-stent restenosis, where the use of these agents has been controversial $(7,25)$. Periprocedural creatine kinase-MB elevation three times the normal occurs in $4 \%$ to $5 \%$ of patients and use of glycoprotein IIb/IIIa inhibitors has been shown to decrease enzyme release $(6,7,17)$. Both creatine kinase-MB and troponin I elevation were higher in our high-risk group, perhaps due to increased distal thromboembolism, which can be further reduced by aggressive antiplatelet therapy and use of distal protection devices (25-27). We found that high-risk patients had a higher incidence of 30-day major adverse cardiac events, perhaps due to increased multivessel coronary disease and complex lesions, and lower left ventricular ejection fraction, as compared with low- or intermediate-risk patients, but none of these factors were independently predictive of 30-day major adverse cardiac events.

Prior beta-blocker therapy at the time of percutaneous coronary intervention has been shown to decrease periprocedural creatine kinase-MB release and long-term mortality (28). In our study, $74 \%$ of high-risk patients were receiving beta-blocker treatment before undergoing the procedure. Likewise, statin therapy has been shown to reduce 30-day and 6-month mortality (29). We found that despite statin use in about $65 \%$ of patients, the average low-density lipoprotein cholesterol level was $121 \pm$ $11 \mathrm{mg} / \mathrm{dL}$, suggesting that further measures should be adopted to reduce levels to $<100 \mathrm{mg} / \mathrm{dL}$.

Our study has several limitations. It was not randomized, and it employed the TIMI risk score retrospectively to predict the risk of outcomes after percutaneous coronary intervention. Patients were followed for only 30 days. C-reactive protein, an important inflammatory marker of adverse prognosis in patients with unstable angina or non-ST-segment elevation myocardial infarction, was not measured and not included in the risk calculation.

In conclusion, although the TIMI risk score has previously been shown to be useful in the risk stratification of acute coronary syndrome patients, it was only modestly predictive in this group of patients undergoing percutaneous coronary intervention. The score alone cannot be used to guide interventional treatment strategy.

\section{REFERENCES}

1. White $\mathrm{H}$, Wong C. Risk stratification and treatment benefits in patients with non-ST-elevation acute coronary syndromes. Eur Heart J. 2002;23:187-191.

2. Morrow D, Antman E, Snapinn S, et al. An integrated clinical approach to predicting the benefit of tirofiban in non-ST elevation acute coronary syndromes. Eur Heart J. 2002;23:223-229.

3. Antman E, Cohen M, Bernink P, et al. The TIMI risk score for unstable angina/non-ST elevation MI. A method for prognostication and therapeutic decision making. JAMA. 2000;284:835-842.

4. Kini A, Reich D, Mitre C, et al. A risk stratification scheme for selection of a glycoprotein IIb/IIIa inhibitor during percutaneous coronary intervention based on clinical and angiographic criteria. Am J Cardiol. 2001;88:1287-1290.

5. Ellis S, Guetta V, Miller D, et al. Relation between lesion characteristics and risk with percutaneous intervention in the stent and glycoprotein IIb/IIIa era: an analysis of results from 10907 lesions and proposal for new classification scheme. Circulation. 1999;100: 1971-1976.

6. Kini A, Marmur J, Kini S, et al. Creatine kinase-MB elevation after coronary intervention correlates with diffuse atherosclerosis, and low-to-medium level elevation has a benign clinical course. J Am Coll Cardiol. 1999;34:663-671.

7. Hong M, Mehran R, Dangas G, et al. Creatine kinase-MB enzyme elevation following successful saphenous vein graft intervention is associated with late mortality. Circulation. 1999;100:2400-2405.

8. Hosmer DW Jr, Lemeshow S. Applied Logistic Regression. 2nd ed. New York, New York: John Wiley \& Sons, Inc; 2000.

9. Zhang H, Singer B. Recursive Partitioning in the Health Sciences. New York, New York: Springer-Verlag; 1999:10-15.

10. DeLong E, DeLong D, Clarke-Pearson D. Comparing the areas under two or more correlated receiver operating characteristic curves: a nonparametric approach. Biometrics. 1988;44:837-845.

11. O'Connor GT, Malenka DJ, Quinton H, et al. Multivariate prediction of in-hospital mortality after percutaneous coronary interventions in 1994-1996. Northern New England Cardiovascular Disease Study Group. J Am Coll Cardiol. 1999;34:681-691.

12. Shaw RE, Anderson HV, Brindis RG, et al. Development of a risk adjustment mortality model using the American College of Cardiology-National Cardiovascular Data Registry (ACC-NCDR) experience: 1998-2000. J Am Coll Cardiol. 2002;39:1104-1112.

13. Moscucci M, Kline-Rogers E, Share D, et al. Simple bedside additive tool for prediction of in-hospital mortality after percutaneous coronary interventions. Circulation. 2001;104:263-268.

14. Singh M, Lennon RJ, Holmes DR Jr, et al. Correlates of procedural complications and a simple integer risk score for percutaneous coronary intervention. J Am Coll Cardiol. 2002;40:387-393.

15. Samaha FF, Kimmel SE, Kizer JR, et al. Usefulness of the TIMI risk score in predicting both short- and long-term outcomes in the Veterans Affairs Non-Q-Wave Myocardial Infarction Strategies InHospital (VANQWISH) Trial. Am J Cardiol. 2002;90:922-926.

16. Fragmin and Fast Revascularization During Instability in Coronary Artery Disease (FRISC II) Investigators. Invasive compared with non-invasive treatment in unstable coronary artery disease: FRISC II prospective randomized multicentre study. Lancet. 1999;354: $708-715$.

17. EPISTENT Investigators. Randomized placebo-controlled and balloon angioplasty-controlled trial to assess safety of coronary stent- 
ing with use of platelet glycoprotein IIb/IIIa blockade. Lancet. 1998; 352:87-92.

18. The Clopidogrel in Unstable angina to prevent Recurrent Events (CURE) trial Investigators. Effects of clopidogrel in addition to aspirin in patients with acute coronary syndromes without ST-segment elevation. N Engl J Med. 2001;345:494-502.

19. The ESPRIT Investigators. Novel dosing regimen of eptifibatide in planned coronary stent implantation (ESPRIT): a randomized, placebo-controlled trial. Lancet. 2000;356:2037-2044.

20. The TARGET Investigators. Comparison of two platelet glycoprotein IIb/IIIa inhibitors, tirofiban and abciximab, for the prevention of ischemic events with percutaneous coronary revascularization. N Engl J Med. 2001;344:1888-1894.

21. The CAPTURE Investigators. Randomized placebo-controlled trial of abciximab before and during intervention in refractory unstable angina: CAPTURE study. Lancet. 1997;349:1429-1435.

22. The PURSUIT Trial Investigators. Inhibition of glycoprotein IIb/ IIIa with eptifibatide in patients with acute coronary syndromes. N Engl J Med. 1998;339:436-443.

23. The PRISM-PLUS Trial Investigators. Inhibition of the platelet glycoprotein IIb/IIIa receptor with tirofiban in unstable angina and non-Q-wave myocardial infarction. N Engl J Med. 1998;338:14881497.
24. Cannon C, Weintraub W, Demopoulos L, et al. Comparison of early invasive and conservatives strategies in patients with unstable coronary syndromes treated with the glycoprotein IIb/IIIa inhibitor tirofiban. N Engl J Med. 2001;334:1879-1887.

25. The SAFER Trial Investigators. Randomized trial of a distal embolic protection device during percutaneous intervention of saphenous vein aorto-coronary bypass grafts. Circulation. 2002;105:12851290.

26. Stone G, Moliterno D, Bertrand M, et al. Impact of clinical syndrome acuity on the differential response to 2 glycoprotein IIb/IIIa inhibitors in patients undergoing coronary stenting: the TARGET trial. Circulation. 2002;105:2347-2354.

27. Kini A, Richard M, Suleman J, et al. Effectiveness of tirofiban, eptifibatide, and abciximab in minimizing myocardial necrosis during percutaneous coronary intervention (TEAM pilot study). Am J Cardiol. 2002;90:526-529.

28. Sharma S, Kini A, Marmur J, et al. Cardioprotective effect of prior $\beta$-blocker therapy in reducing creatine kinase-MB elevation after coronary intervention. Benefit is extended to improvement in intermediate-term survival. Circulation. 2000;102:166-172.

29. Chan A, Bhatt D, Chew D, et al. Early and sustained survival benefit associated with statin therapy at the time of percutaneous coronary intervention. Circulation. 2002;105:691-696. 